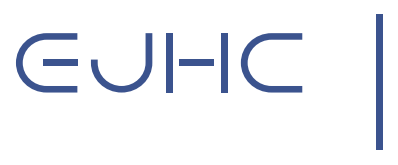

\title{
Health-Related Decision-Making of People with Thyroid Disease
}

\section{The Role of Connective Action and Politicisation of Illness Identities}

\section{Judith Schossböck}

Department of Media and Communication, City University of Hong Kong, Hong Kong SAR

\begin{abstract}
Social networking sites have become increasingly important for self-diagnosis and obtaining health information, which are particularly relevant in the context of a lack of care. Their structures can further encourage the politicisation of health topics, as they offer a space for the production of crowdsourced knowledge and the amplification of activist content. Hence, it is important to examine how online discourse shapes the decision-making of specific patient groups. This article uses the conceptual lenses of health activism, connective action, and politicised illness identity to investigate health-related decision-making of people with thyroid disease. Drawing on a participatory netnography within activist spaces and 33 in-depth interviews, the study identifies contemporary decision-making paradigms and discusses the role of connective action and politicisation in this context. A typology based on salient strategic themes of decision-making is proposed. The results provide valuable input for researchers of illness identities, as well as practitioners who need to consider different patient types. They contribute to the study of socio-political dimensions of health and an increasingly important discourse that has so far been under-investigated by health communication research.
\end{abstract}

\section{Keywords}

Health activism, illness identities, connective action, netnography, thyroid disease 
Health communication research has pointed out the increasing importance of social networks for obtaining health information (S. Fox \& Duggan, 2013) and health-related decision-making (Leahey et al., 2015; Valente, 2010). Online support groups offer many affordances for people with chronic illnesses, such as "crowd-sourced processes of health knowledge sharing" (Vicari \& Cappai, 2016, p. 1), which is particularly relevant alongside the reduction of care services (Das, 2019). Medical anthropology has investigated how participation in online support groups affects illness identities (Sobo et al., 2016). Less is known about how the decision-making process of health-seeking subjects is shaped by online discourse and how this might affect health-related subjectivities (Giraud, 2015; Ortner, 2005) for chronic conditions.

Exploratory research focusing on thyroid patients has noted some dissatisfaction by people with thyroid disease with the nature of knowledge communicated by professionals (Ulvenblad, 2020). People seek alternative information online and navigate different sources of amateur or professional origin. As some patients find that the information they receive online is more useful than the one from physicians (Diaz et al., 2002; Ulvenblad, 2020), social media has the potential to transform the nature of health decision-making. To understand all patients' needs, we must get a better understanding of this process, and include discourse that challenges medical dominance. Hence, this article uses the conceptual lenses of health activism, connective action, and politicised illness identity for analysing different socio-political dimensions of decision-making.

Health activism refers to the creation of alternative health knowledge and often opposes traditional notions of medical authority (Laverack, 2013; Zoller, 2005). The discursive dynamics on social media can support actors of health activism, as "non-elite actors" organise around issues online (Vicari, 2017, p. 3), leading to an expansion of health discourse. The concept of "connective action" (Bennett \& Segerberg, 2012; Vicari \& Cappai, 2016, p. 1666) is useful for studying healthrelated decision-making as it addresses the sharing of personalised content on social media (Bennett \& Segerberg, 2012; Postill, 2015), and helps in investigating the role of digital media in challenging dominant paradigms (Vicari, 2017). The concept of politicised illness identity (N. Fox \& Ward, 2006; P. G. Klandermans, 2014; Zoller, 2012) links illness to existing inequalities, and thus offers an important lens for investigating the role of politicisation in this context.

The case of thyroid disease was selected because it represents a common chronic illness with increasing global impact (Moini et al., 2020) and a diverse online discourse. Moreover, this paper contributes to the study of the online health behaviour of a patient group that has been understudied from a socio-political perspective (Winterich, 2011).

Based on a netnography (Kozinets, 2015) and a network of health activists and advocates, the paper reports data from 33 in-depth interviews of people with thyroid disease. This method is appropriate for the study of cultures in online environments and offers the opportunity to create data on otherwise less openly accessible aspects. Such data is often sensitive, and some patients are rather critical towards representatives of medical authority. Investigating these cultures thus demands immersion in the field to gain trust, providing researchers a chance to access unique data from such contexts (Kozinets, 2015). 


\section{Literature Review}

\section{Thyroid Disease}

Thyroid disease is a chronic condition with increasing worldwide relevance and potential high societal costs (Perumal et al., 2015; Tarricone, 2006; Ulvenblad, 2020). It is one of the leading endocrine disorders, representing around $30 \%$ to $40 \%$ of patients in endocrine practice (Madariaga et al., 2014). The American Association of Clinical Endocrinologists estimated that approximately 13 million people $(4.78 \%)$ in the United States have undiagnosed thyroid dysfunction (Garber et al., 2012). Nearly $11 \%$ of Europeans have thyroid dysfunction (Madariaga et al., 2014). There are different forms of thyroid disease with or without an auto-immune component: hypothyroidism, hyperthyroidism, Hashimoto's thyroiditis, Grave's disease, thyroid nodules, thyroid cancer and conditions resulting from partial or total thyroidectomy. ${ }^{1}$

Activist groups for thyroid disease in the United States, Canada and the United Kingdom fight for more awareness and better treatment access, while groups in Nigeria oppose stigmatisation. Central to the global online discourse are challenges to the medical authority (Brown et al., 2004) regarding discrimination, treatment and access, ${ }^{2}$ non-standard medication, and alternatives to surgery. Different illness identities bring conflicts about health belief systems. Awareness is enhanced with the use of symbols, such as a light blue ribbon or a butterfly. Among the first patient-led activist groups was the bottom-up site Stop the Thyroid Madness, which has been joined by many other non-elite actors. Another example is Improve Thyroid Treatment (ITT), a group in the United Kingdom that became active in June 2017, when patients mobilised after the withdrawal of liothyronine medication from the market (ITT, 2017).

\section{Health Activism}

Health activism has long been overlooked as an important element of health communication (Zoller, 2005). As an interdisciplinary lens it brings attention to the influence of activism on health and illness identity. Health activism is defined as alternative discourse that challenges mainstream health care and paradigms (Zoller, 2005) or as resistance to the dominant medical profession (Laverack, 2013). Health activists create alternative knowledge and challenge traditional notions of medical authority (Vicari \& Cappai, 2016), often blurring the distinction between lay people and professionals. The structures of social media with new forms of patient engagement (Vicari \& Cappai, 2016) and increased visibility of unauthorised information (Viviani \& Pasi, 2017; Waszak et al., 2018) complicate this process, as they influence the visibility and credibility of health activist groups. $^{3}$

Previous research has put forward various frameworks for health activism (Zoller, 2005, 2012). However, more clarity is needed about its role for health-information-seeking subjects in contemporary media environments, as well as emerging forms of action. We need to understand the politicisation of such discourse and tap into the context and variables of health activism to investigate its validity. 


\section{Connective Action}

Assuming that the structures of social networking sites can support the politicisation of health topics, it is important to examine the role of such phenomena. Previous research has acknowledged the importance of non-elite actors (Vicari, 2017) in health decision-making and applied the concept of connective action to the health domain (Vicari, 2017, p. 3). These studies underlined that such actors can challenge our understanding of established knowledge because they can become primary sources of information, supported by the discursive dynamics on social media (Vicari, 2017).

Digital networking mechanisms ease online health information seeking (Balka et al., 2010) and offer a context for the production of crowdsourced health knowledge (Bimber et al., 2005, p. 372; Vicari \& Cappai, 2016, p. 1666). The "logic of connective action" (Bennett \& Segerberg, 2012), a concept referring to new patterns of participation in contemporary politics, proposes that these discourses are more crowd- than organisation-based, which helps to expand the discursive space around political issues. Central to this observation is the rise of a more personalised digitally networked politics in which diverse individuals gather to address contemporary issues (Bennett \& Segerberg, 2013). Digital media play an important role in facilitating these personalised processes, which allows individuals to activate their own loosely tied social networks (Bennett, 2012). While this concept has been recognised in works on political activism, it has not yet been included in frameworks of health activism.

Personalised information plays a big role for today's "participatory patients" (Gardiner, 2008), who often navigate many different narratives of both an expert and a crowdsourced nature. Due to the dynamics of social media, such content is embedded in a struggle over credibility (Neumayer \& Rossi, 2018), and unauthorised, contentious or antagonist content might be amplified (Farkas et al., 2018; Phillips, 2018). Shared information by patients thus acts as a challenge to medical dominance (Lupton, 2012). Moreover, declaring "truth" based on autonomous expertise only as opposed to a collectively formed opinion can even suggest irrelevance today (Singer, 2008), as people aggregate around shared beliefs that challenge dominant paradigms. Individual and anecdotal narratives can promote suspicion "regarding variables that science has not yet accounted for" (Sobo et al., 2016, p. 540). Thus, investigating the role of connective action and crowdsourced content for different patient groups and their health decision-making is crucial.

\section{Politicised IIIness Identity}

Illness is not simply defined in terms of anatomy or physiology, but also a political category related to physical and cultural possibilities and constraints surrounding the body. (N. Fox \& Ward, 2006) As identities emerge within the contexts of these possibilities, illness can be seen as an identity practise (N. Fox \& Ward, 2006).

Illness identity is defined as the degree to which a chronic health condition is integrated into someone's identity (Charmaz, 1995; Van Bulck et al., 2019). This can be related to political factors or structural inequalities, such as gender, migration and social status (Zoller, 2005). Illness identities have been studied with theoretical frameworks ranging from expert patients to resisting consumers. (N. Fox \& Ward, 2006). According to a social psychological model, people can show 
a politicised identity to the extent that they self-consciously engage in a power struggle on behalf of a group (Simon \& Klandermans, 2001).

For a political illness identity (P. G. Klandermans, 2014) to arise, it is commonly linked to a social critique addressing inequalities (Brown et al., 2004). Shared grievances, next to adversarial attributions and action, are notable components of illness identity (Simon \& Klandermans, 2001). Identity politicises when it becomes the focus of a "struggle for power" (P. G. Klandermans, 2014, p. 4). When "identification with a superordinate entity declines" (B. Klandermans, 2004, p. 4; Van Stekelenburg et al., 2013), discontent results in radical action. Applying this to health activism, superordinate identities could be groups, belief systems, medical paradigms or representatives of a medical establishment. Politicised illness identity thus creates common bonds among sufferers, linking illness to inequalities (Brown \& Zavestoski, 2004; Zoller, 2005).

\section{Research Questions}

This study aims to offer a socio-political perspective to the study of online health-seeking behaviour by answering the following research questions:

$R Q 1$ : How do people with thyroid disease who are active on social media make healthrelated decisions? What strategic themes of decision-making can be derived?

$R Q 2$ : What is the role of connective action in the health-related decision-making of people with thyroid disease who are active on social media?

$R Q 3:$ What is the role of politicisation in the health-related decision-making of people with thyroid disease who are active on social media?

\section{Methods}

\section{Participatory Netnography}

The reported results are part of an auto(n)ethnographic, phenomenologically informed inquiry (Pitard, 2019; Sloan \& Bowe, 2014; van Manen, 2007) into health activist discourse about thyroid disease on social media, applying a cross-platform approach. Data were generated from participatory netnography (Kozinets, 2013, p. 67) with continuous online participation (Caliandro, 2018; Kozinets, 2013). Netnography is an ethnographic research tool that applies traditional techniques of cultural anthropology to online environments and is suitable for the examination of network culture (Kozinets, 2013). Figure 1 gives an overview of the research design.

The research was conducted in different stages, from prolonged passive engagement to active participation (Kozinets, 2013, 2015). In the first phase, from April 2017 to October 2018, I followed an embedded strategy (Hine, 2015) by observing a variety of non-elite actors on social media. I concentrated on Facebook and Twitter, where a wide variety of activist discourse was displayed. In line with the auto-ethnographic nature of the study, the data comprised all forms of thyroid disease ${ }^{4}$ but were influenced by my illness identity and network, which were created and reflected through "a human filter of immersion and experience" (Kozinets, 2015, p. 185). This stage helped with the initial orientation before the entry into the field ("entrée") (Kozinets, 2015, p. 29) and the case selection (stage 2). ${ }^{5}$ The participative phase (Kozinets, 2015) from November 
2018 focused on connecting to activist spaces via critical case sampling. ${ }^{6}$ Field notes, screenshots and textual and visual data were collected. In contrast to more passive methods (Wallace et al., 2018), participatory netnography demands full transparency about the researcher's identity (Kozinets, 2015; Wallace et al., 2018), which was achieved through the entrée, a personal blog and the use of transparent account names. After the entry in October 2018, a pre-study of 17 interviews was conducted with activists and advocates who answered the call for interviewees on their sites and newsletters. This was followed by in-depth qualitative interviews with 33 people with thyroid disease via WhatsApp, Facebook Messenger, Skype or Discord. I also participated in the activist group ITT $^{7}$ on Facebook and followed case-specific hashtags. Other ways of "participation and doing" (Kozinets, 2013, pp. 91-97) included e-petitions, reviewing medical statements, filling out questionnaires, an invitation to take part in a national thyroid patient conference $^{8}$, and being available for tasks within the activist group.

\section{Reflexive Aspects}

The research stages were supported by a WordPress blog (Connective Health Action) used to present the research background, information on consent, researcher persona and content updates. I also created pages on social media, namely Researcher CityU on twitter Judith Schossboeck (Researcher) on Facebook. The research framework includes a reflexive component addressing the subjectivity of the research (Primeau, 2003), which allowed personal experience to influence data gathering (Mcmanus Holroyd, 2007; Sloan \& Bowe, 2014). My illness history started with a thyroid autonomy, cold and hot nodules and a thyroidectomy due to cancer suspicion in 2014 . This helped enhance my understanding of the medical background and strengthened the integrity of the ethnographic research (Wallendorf \& Russel, 1989). ${ }^{9}$

\section{Content Selection}

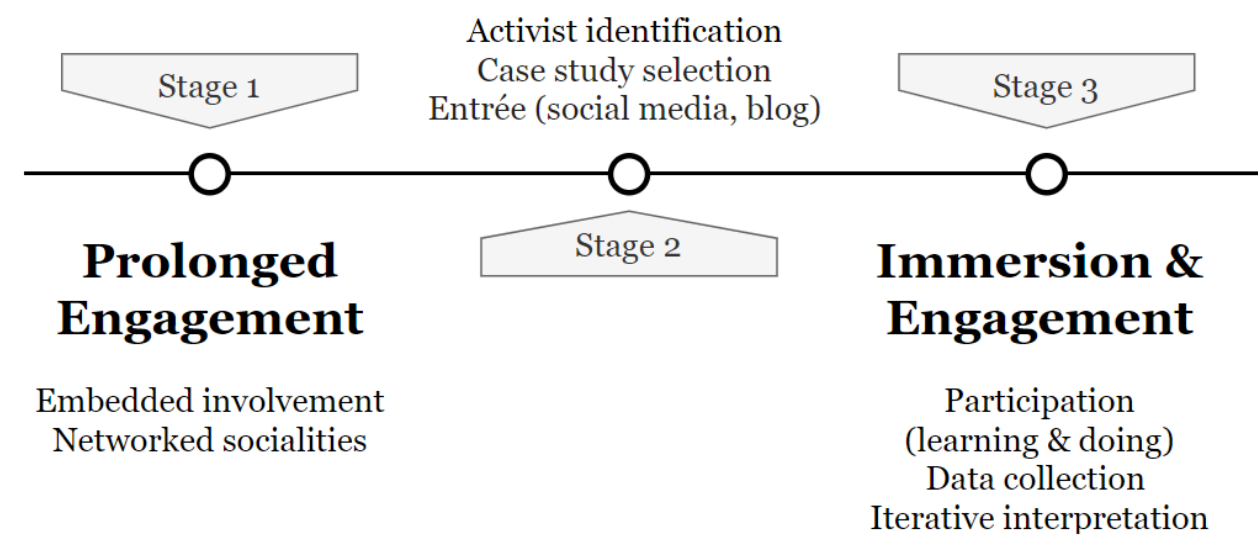

Figure 1. Netnography: Stages of the Research Project 


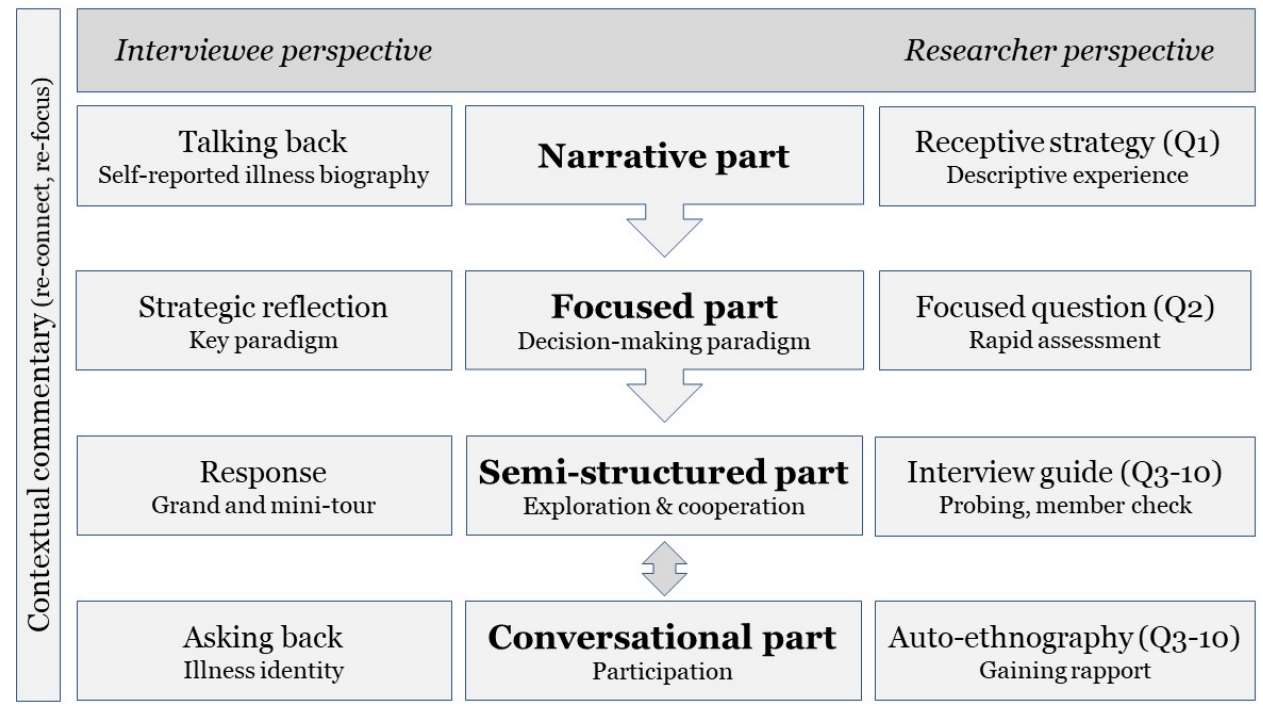

Figure 2. Interview Method

Throughout the study, different identities - researcher, patient and activist - mutually informed each other, which has led to two methodological additions that facilitated understanding. The first was the voluntary application of practices shared by activists in my medical context. I tried to use the strategies of activist sites for accessing medication and tried various thyroid treatments, including variants that differed from the standard medical protocol, such as natural desiccated thyroid and slow release trijodthyronin (T3). While this practice might hold some risks, this firsthand context helped increase my understanding of the lifeworlds of those who fight for nonstandard treatment. The second addition concerns the analytic reflexivity of auto-ethnographic involvement. To address the subjective nature of the study (Primeau, 2003) and its effects on data gathering (Cresswell, 2007; Sloan \& Bowe, 2014), an inductive analytic approach (Glaser et al., 1967) was used to reflect on identifications. Auto(n)ethnographic aspects of my identity were coded in the interviews. This strategy of ethics in practice (Guillemin \& Gillam, 2004) showed that most self-references were made as a patient (40\% of reflexive statements), followed by researcher (24\%) and activist (14\%). This further highlighted other identities: member of a specific healthcare system (11\%), member of a family with prevalent thyroid disease $(10 \%)$ and woman (1\%). An analysis of the distribution of these references with a code matrix showed that I provided various reflexive statements in the majority of interviews. This revealed that the patient perspective played a bigger role in guiding the conversations than initially intended, ${ }^{10}$ and it illustrated less conscious elements of the speaking position. Gender, a significant theme emerging from the interviews, was mostly brought up proactively by participants and not provoked by my reflexive statements of self-identification.

\section{Interview Method and Sampling}

Participants were recruited for in-depth interviews via Voice over Internet Protocol. The pre-study involved 17 in-depth interviews with activists, followed by 33 in-depth interviews with people with thyroid disease. 
Table 1. Demographics of Interviewees

\begin{tabular}{|c|c|c|}
\hline & $n$ & $\%$ \\
\hline \multicolumn{3}{|l|}{ Gender } \\
\hline Female & 31 & 93.9 \\
\hline Male & 2 & 6.1 \\
\hline \multicolumn{3}{|l|}{ Disease type } \\
\hline Hypothyroidism & 23 & 69.7 \\
\hline Hyperthyroidism & 5 & 15.2 \\
\hline Thyroid cancer & 3 & 9.1 \\
\hline Other & 1 & 3.0 \\
\hline $\mathrm{N} / \mathrm{A}$ & 1 & 3.0 \\
\hline \multicolumn{3}{|l|}{ Age } \\
\hline $20-30$ & 3 & 9.1 \\
\hline $31-40$ & 6 & 18.2 \\
\hline $41-50$ & 13 & 39.4 \\
\hline $51-60$ & 7 & 21.2 \\
\hline $61-70$ & 4 & 12.1 \\
\hline Mean $(S D)$ & \multicolumn{2}{|c|}{$46.2(10.8)$} \\
\hline \multicolumn{3}{|l|}{ Country } \\
\hline USA & 8 & 24.2 \\
\hline UK & 13 & 39.4 \\
\hline Ireland & 5 & 15.2 \\
\hline New Zealand & 1 & 3.0 \\
\hline Canada & 4 & 12.1 \\
\hline Norway & 1 & 3.0 \\
\hline Romania & 1 & 3.0 \\
\hline \multicolumn{3}{|l|}{ Time on social media } \\
\hline Mean $(S D)$ & \multicolumn{2}{|c|}{$163.3(109.2)$} \\
\hline \multicolumn{3}{|c|}{ Interview duration in minutes } \\
\hline Mean $(S D)$ & \multicolumn{2}{|c|}{$45.3(11.8)$} \\
\hline
\end{tabular}

The 33 semi-structured interviews reported in this article were conducted in February and March 2019. The interviews lasted 45 minutes on average $(M=45.30 \mathrm{~min})$ and were based on a semi-structured guide comprising of 10 items. Figure 2 depicts the methodological framing of the interview process.

The study followed a purposeful interview sampling strategy by using contacts from the netnographic participation and the pre-study with health activists and advocates who supported my request on their blogs, social media accounts and newsletters $(5,688$ users were counted for these accounts and 4,000 recipients for newsletters). Additionally, I used my personal blog, Facebook page and Twitter hashtags (e.g. \#thyroid, \#hypothyroidism, \#hyperthyroidism and \#thyroidcancer) to promote the call. To attract a wide range of participants, including more casual users (Klitzman et al., 2007), interviewees received compensation in the form of gift cards (university funding). Related to this are aspects of data validity (Bentley \& Thaker, 2003) and the 
possibility that subjects might frame their experience in a way they think is favourable (Klitzman et al., 2007); this was counteracted by the immersive nature of the study and measures for gaining rapport. ${ }^{11}$ As the sampling method might oversample more active users, it must be pointed out that this study does not create data for assessing the extent of politicisation in discourse about thyroid illness. However, it can provide valuable insights into its context.

Participants consented to the interview procedures by agreeing to a statement on my blog. Coding was done with the data analysis software MAXQDA 2018 following a deductive approach (drawing on health activism and illness identities), followed by an inductive one (Böhm et al., 2004) aimed at deriving strategic themes and emerging practices. Regarding procedural ethics (Guillemin \& Gillam, 2004), the application for ethical review of research involving human participants was endorsed by City University of Hong Kong on 8 April 2018. Interview guidelines were pretested with patients and structured in three parts: 1) personal decision-making and information curation (Q1-Q4), 2) evaluation of content and impact (Q5-Q7) and 3) health activism and politicisation $(\mathrm{Q} 8-\mathrm{Q} 10)$.

Table 1 presents the interviewees' demographic characteristics, including their age, gender, region, disease type and time spent on social networking sites. Most respondents had hypothyroidism, including Hashimoto's $(n=23)$; the rest had hyperthyroidism or Graves' disease $(n=5)$, thyroid cancer $(n=3)$ or other thyroid conditions $(n=1) .{ }^{12}$ In line with the gender distribution for thyroid disease, 31 interviewees were female.

\section{Results}

\section{Decision-Making Paradigm}

The first part of the interview consisted of a highly focused question addressing general decisionmaking, ${ }^{13}$ followed by questions on information curation, from which distinct themes were deduced (RQ1). Most interviewees named a variety of non-elite actors, most often the site Stop the Thyroid Madness. This resource was described as an important inspiration (P01, P33) based on patient experience (P03) but not generally seen as trusted source due to the nature of content presentation (often perceived as too prescriptive). Other favoured activist groups were the Canadian Thyroid Patients ("real activists", $\mathrm{P} 18^{14}$ ) and ITT, a group that is specifically set up to share content and discover commonalities (P06). There were divergent views on the trustworthiness of information on social media. Aggregated information in the network stimulated a closer look, particularly when such information was encountered repeatedly by similar people. Similar to clusters found in previous research (Nelissen et al., 2017), the data suggest important distinctions related to medical paradigms and lifestyle. Many patients emphasised the natural as important (13 interviewees); others saw lifestyle aspects, such as nutrition, as an important area of treatment. ${ }^{15}$

The first dimension of the following depiction of salient strategic themes is related to health activism, the second to illness identity. A large proportion of interviewees expressed a politicised illness identity (Simon \& Klandermans, 2001) linked to superordinate identities (Klandermans, 2004; Van Stekelenburg et al., 2013), such as endocrinologists, Big Pharma or a rigid medical 
system. For many, this led to an activist stance, with people acting as non-elite actors to support activists' point of view. Others took a more conformist stance and appreciated the affordances of social media for the formation of a collective illness identity, valuing established knowledge. For politicised illness identities, crowd wisdom was not necessarily considered better than expertgenerated narratives. Most people used an assembly of sources, emphasising their responsibility not to trust isolated information. However, they differed in their understanding of what constitutes knowledge authority and trusted content. Related to these findings, a Cartesian grid depicting strategies and standpoint themes was derived (Figure 3). Patients can exhibit multiple standpoints but tend to be situated on either the upper or lower hemisphere.

The upper part in Figure 3 symbolises people expressing a politicised illness identity who tend to follow an alternative route of decision-making. They value challenges to the medical authority as fact checkers, look for alternative evidence and are oriented towards content that offers an alternative route to information. In another dominant paradigm, people rely heavily on information within the online community and participatory knowledge, and they can become embodied activists. The lower part of the grid symbolises the expression of a connected illness identity oriented towards a conformist stance and an established system. People express two major decision-making paradigms oriented towards either established expertise ("informed conformity") ${ }^{16}$ or knowledge of similar people on social networking sites ("shared authenticity"). People can move between strategic themes; for instance, a person relying on information based on "shared authenticity" in an online self-help group can move towards an activist stance by engaging in radical self-treatment and relying on information from the community ("community reliance") due to restricted access to treatment or other contexts of politicisation. Patients often self-diagnose and interpret test results based on participatory knowledge.

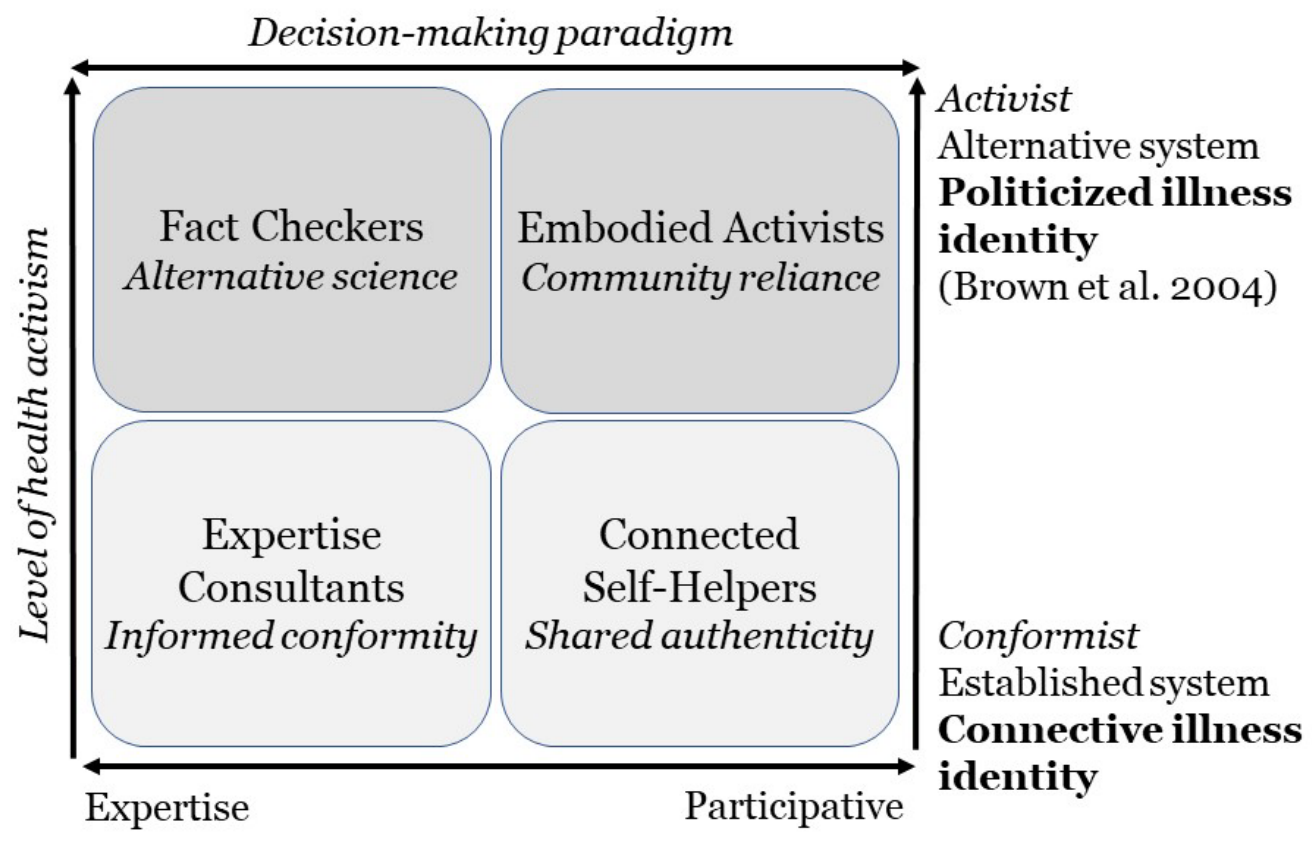

Figure 3. Cartesian Grid: Strategic Stance and Salient Dimensions 
Most individuals expressed a pro-scientific stance. At the same time, there was a noticeable trend in the data that opinion-making disregards information that is isolated from patient experience. Sources of established expertise (e.g. PubMed, Thyroid UK and the Dr Thyroid podcast) were consulted in combination with alternative experts (e.g. Dr Isabella Wentz, Mary Shomon, Hypothyroid Mum, Amy Myers and Paul Robinson) and collectives that aggregate information (e.g. Canadian Thyroid Patients, ITT Campaign, Stop the Thyroid Madness, Thyroid Nation and Thyroid Change).

Some disease types with complex needs might be predisposed towards a strategic stance of community reliance, for example in this person's case: "I have no one else to trust. I have Hashimoto's [laughs]; it's very, very poorly treated" (P25). Such illness identities rely more exclusively on strategies from the community: "So you just have to trust them ... I think it was online, someone said, you will have to become ... the expert" (P25). For the three interviewees who received treatment for thyroid cancer, both conformist and activist standpoints were found. For example, one thyroid cancer patient displayed a stance of informed conformity: "I had a great doctor. I have a great surgeon. I really like my endocrinologist. I think I didn't want to go through surgery, but it is something that had to be done. ... I don't have any complaints" (P10).

Within the conformist stance, people still engage in self-help online; however, they often decidedly distance themselves from relying solely on the community, for instance, regarding blood work evaluation: "I don't get copies of my lab work like some people do. I don't dissect it the same way." (P33).

Within the alternative science stance, people emphasised the importance of alternative expertise providing different content, which they felt was not provided by the established system: "I do a lot of reading on sites like Stop the Thyroid Madness ... because they have a lot of evidence-based material ... And I know medical practice is like 20 years behind the actual research" (P24).

\section{Role of Connective Action}

Several strategies stemming from a stance of community reliance (Figure 3) emerged regarding connective action (RQ2). The most frequently mentioned ones were framed as "selective doctor exposure" and "medical tourism". Patient-led online groups have been creating resources to classify doctors according to their openness to activist claims. As one interviewee mentioned, "There is a lot of local information that people share about different doctors, and they can tell people 'Don't waste your time with that person' ... we can speed things up for people" (P12).

Another strategy concerns the acquisition of unsupported medication, such as liothyronine or natural desiccated thyroid, which can be inspired by participation on social networking sites: "Because many doctors won't prescribe it. Many of them will be sourcing their supplies overseas" (P23). Asked about the inspiration to source medication, community reliance was emphasised. For instance, one patient said that reading other people's comments encouraged her to source the medication (P15). Two main strategies of medical tourism - sourcing alternative medical supply from abroad - were identified: 1) sourcing medication by ordering from a medical system outside one's own country and 2) importing in person, for instance, when going on vacation. For example, P15 narrated how the natural desiccated thyroid arrived from America. 
Resistance from the system in combination with inspiration from similar people contributes to this strategy: "They don't want to give it [liothyronine] to you on the NHS [National Health Service, UK]. But I don't know, people seemed to think that it was better. So I ordered some from a place, Thailand" (P27).

Other places mentioned to source medication were France, Spain, Greece and Turkey (P23, P11). Patients also referred to cost and safety in this context: "And you want somewhere safe to get your medication" (P25). Medical tourism was favoured due to the rising costs of off-standard medication or the availability of such medication in the over-the-counter market: "But you can actually walk into a Greek pharmacy ... same in Turkey" (P11). Six interviewees mentioned that they engaged in sourcing medication that way, and 14 mentioned that they knew someone in their network who engaged in medical tourism.

In sum, connective action can influence important health-related decisions concerning unestablished treatment forms. While this adds to patient empowerment, it also clearly circumvents regional regulations, possibly detaching people further from the official care system. Through the sharing of options off the standard paradigm, social media amplifies the visibility of such action and provides a platform for the politicisation of the debate.

\section{Role of Politicisation}

Several dimensions of politicisation related to medical paradigms, personalisation, gender and power dynamics were expressed (RQ3).

Decline in Identification with the Dominant Paradigm. This dimension relates to the criticism of standard medication and testing. Patients expressed their need for more comprehensive testing and alternatives to classic medication. Relying on the thyroid stimulating hormone (TSH) value alone was perceived as outdated. People even framed this standard test as "unreliable" in terms of measuring well-being (P29), and framed reliance on the TSH value as a hurdle to getting better (P12, P14). The dominant paradigm was also reinterpreted: "TSH isn't produced by the thyroid; ... Why not focus on what your thyroid is actually making?” (P24).

The comparison of laboratory ranges in global discourse added to critical awareness: "And that worries me, that even in this country, there's such a range of differences" (P08).

Another theme regarding the contestation of the standard paradigm is what can be framed as the T4/T3 controversy or "T3 inequity". ${ }^{17}$ In this context, the argument for an extension of treatment options is not solely based on the idea that the natural is superior. Instead, it is argued that a subgroup of patients needs different medication: "They call it their gold standard T4 synthetic drug, and I know well it's not gold standard, because I am still sick 20 years later" (P32).

The standard protocol is often framed as a belief system in contrast to an independent view of science: "They need to look at the studies, the independent studies, that are not done by the companies that sell the drugs" (P12).

The participants argued for an extension of the dominant protocol from two perspectives: 1) an emphasis on the natural and 2) the proclamation of a subgroup of thyroid patients with specific needs. 
Lack of Personalised Institutional Support. Online support groups have become a popular strategy of resistance for those disaffected with medical dominance (Lupton, 2012). As patients are moving from being consumers of healthcare information to producers, what they perceive as lacking can be provided by online resources. These aspects can be boiled down to personalised care, bio-individual treatment and a focus on the "whole picture" (P32): "Going to the source instead of just trying to mask [the symptoms] with the medication" (P33).

Alternative online experts, such as Isabella Wentz (mentioned by 11 people), contribute to this approach by offering theories on root causes. Patients perceived lifestyle as an important part of treatment (P23) that is often missing in standard care: "There's no individuality at all in the treatment of thyroidism" (P32). This was even more prevalent for those with autoimmune thyroid disease (P12). Some argued that thyroid disease needs personalised treatment routes because there are diverse patient types with co-diseases, affecting each patient differently (P16, P18). The credibility of non-elite actors was strongly related to their personalised views, as expressed by P09 when discussing the site Hypothyroid Mum: "Because it's all her own personal views backed up by research that she's done."

Gender and Representation. Gender was predominantly mentioned in the context of prejudgements typical of thyroid illness. This is related not only to the demographics of thyroid disease ("8 to 9 times more women have thyroid illness", P23) but also to perceived issues of representation ("And most of the endocrinologists are male, and they minimize the symptoms", P25). Female doctors were perceived as more understanding: "She's a woman, so I feel like she listens" (P02). A patient who described her doctor's resistance to upgrade her medication did so from a gendered stance displaying power dynamics: "It was like a naughty girl asking for more sweets. And I got slapped down all the time" (P09). Framed as issues of "sexism" (P23) or female issues (P11) were problems with not receiving the proper dosage of treatment $(\mathrm{P} 23)$. This ties in with the perception of women with thyroid disease as mad (P06) or "crazy" (P20) and the psychosomatic elements of being a middle-aged female (P06). Many emphasised that it would be easier to get antidepressants (P22) than to get "a different kind of medication" (P12).

Patients speculated about the better quality of medical care they would receive if thyroid disease were not a gendered issue: "If men had to put up with it, they would sort it out" (P11).

Some aspects of gender discrimination correspond with characteristic symptoms of thyroid illness, contributing to gendered prejudgements, such as being lazy, not eating properly, not exercising, and emotional lability (P06). Some women defined strategies to overcome issues of male prejudgement, ironically, for instance, by taking a male advocate to the doctor: "I'm a welleducated professional woman ... but when I need to have a consultation ... I need to take my husband" (P11). 
Power Dynamics and Resistance. The condition influences the patient's capacity to resist medical dominance (Lupton, 2012). In this context, some interviewees held the idea that there are different capacities within thyroid illness, as the fatigue component affects people's ability to resist. The perception of resistance was mostly related to access to medication. People expressed themselves within rhetorical frames, citing war, fights, or begging: "There are patients who are not well on levothyroxine, and if they are not, we shouldn't have to fight" (P15). This rhetorical stance is reflected, for instance, in the names of thyroid patients, who often call themselves "thyroid warriors" (P09). While power differentials do not have to be viewed as a negative part of medical encounters (Lupton, 2012), the perceived resistance in this case is most often found in relation to rigid treatment protocols. Patients used a rhetoric of dominance to express this: "And almost one single dosage would be allowed. You are not allowed to say you have other symptoms" (P25).

Superordinate identities within a framework of power dynamics can be not only doctors but also official institutions: "Because it was the NHS that took my thyroid, but they don't want to give me back all the hormones" (P02).

Power relations applied more to medical belief systems than to the perception of a bad medical establishment: "He's a good doctor. But when I mentioned being on desiccated thyroid, he just laughed, like I would be on snake oil." (P06) However, there were also positive accounts of doctors who perceived treatment options as the patient's right (P15).

\section{Discussion}

\section{Participatory and Personalised Views: Between Conformist and Activist}

This study depicted several decision-making paradigms related to illness identities for thyroid disease (RQ1). While most patients consulted a variety of non-elite actors, various decisionmaking paradigms related to knowledge creation were identified. Activists and conformists could switch between standpoint themes and consult both expert-generated and participatory narratives. This reflects the polyvalent nature of truth creation in today's network environments (Sobo et al., 2016, p. 543). Group authority does not generally override individual expertise, but the latter is rarely sought apart from a participatory narrative. The politicisation of illness identity was identified as a good reference point for depicting different standpoints related to the upper and lower hemispheres of the proposed typology. For thyroid patients, this was linked to the perception of superordinate identities such as endocrinologists, Big Pharma, or a rigid medical system. While previous research has framed illness identities along the poles of expert patients and resisting consumers (N. Fox \& Ward, 2006), those in contemporary environments seem more diverse than that, as resistance and focus on expertise are not mutually exclusive. Health communication research should acknowledge these findings and the diversity of contemporary decision-making paradigms.

\section{Social Media Fosters Strategies of Connective Action}

Social media can foster a mindset of participatory exchange, leading to several strategies of connective action (RQ2) stemming from a stance of "community reliance" and a more personalised 
view of illness. The stance of "community reliance" in the politicised mode seems to foster strategies of connective action. Patients described strategies, such as "selective doctor exposure" and "medical tourism", which shows that participation in the network brings people into contact with ideas that can circumvent dominant practice. This offers valid albeit not always preferred alternatives for patients who perceive resistance from the system and who become politicised. This is not to say that decision-making is not fact-based or anti-science. Herein lies one of the complicated aspects of the creation of "truth" in today's "technocultural context" (Sobo et al., 2016): Participatory views are seen as crucial to backing up information from more established sources, and alternative experts often not only cite scientific information but also present more personalised routes to care, or alternative treatment. It is important to recognise these developments to create useful content and services for patients reflecting different illness identities (N. Fox \& Ward, 2006), alternative ways of treatment, and personalised forms of care.

\section{The Need to Further Examine the Role of Politicisation}

The dimensions regarding the role of politicisation derived in answer to RQ3 include a decline in identification with superordinate identities and paradigms (B. Klandermans, 2004), a perceived lack of personalised support, gender and representation, and power dynamics. These hold important clues regarding treatment options that need more investigation by the medical community.

Whether a person follows a more activist or conformist route is related to different contextual factors. Despite a lack of evidence on the extent of politicisation within the population of people with thyroid disease due to the sampling strategy, several contextual dimensions were derived. Research should look into disclosing relations between disease type, demographic factors and the extent of politicisation. Furthermore, a subgroup of patients appears to have additional needs that are not sufficiently recognised by mainstream care. Social media platforms offer such patients the means to address this lack in care systems. Nevertheless, such discourses would benefit from expert-centred knowledge authorities, for instance, on official platforms.

Looking at the challenges and claims expressed by politicised patients, thyroid disease activism can be framed as an embodied health movement (Zavestoski et al., 2004) because it displays many of its characteristics; for example, it challenges science on diagnosis and treatment options. Such classification can help with distinguishing such content from forms of misinformation.

While connective action inspires views that are different from the classic medical paradigm, additional research is needed to determine the extent of politicisation. Considering common themes within this discourse, it is important to medically evaluate the arguments of activists and lay experts (Epstein, 1995, 1996). Conflicts between the transformative and reformative spheres of health activism (Zoller, 2005), such as the question of which identifications and claims are representative of all thyroid patients, demand further investigation.

\section{Limitations}

The limitations of this study lie in its focus on one health domain, although abstract formulations might allow for a basic degree of generalisability (Böhm et al., 2004). Moreover, the analysis of English-speaking content includes a bias towards more privileged and active social media users, 
and various global medical systems need to be considered (Orgad, 2006). Nevertheless, this approach shows that similar mechanisms, such as access to treatment or gendered injustice, are at play in different countries. In this regard, connective action helps with the facilitation of alternative practices that are found across systems.

The limitations of the sampling method must be stressed, particularly regarding claims about the extent of politicisation. The conformist view is likely more common outside health activist networks. However, this study provided insights into the context of politicisation, pointed to the existence of politicised illness identities for people with thyroid disease who are active on social media, and identified several emerging practices related to crowdsourced knowledge.

\section{Conclusion}

The patients' perspective is often underappreciated by the professional community (Ulvenblad, 2020). The present study thus provides important content for researchers and practitioners who want to consider different audiences and better recognise patients' subjectivities and potential to contribute to the medical discourse. This inquiry confirmed the importance of connective action for decision-making and identified the context of politicisation for one particular patient group. It contributes to advancing the field of social media communication in contemporary health regimes by exploring the online spaces of a health issue and the differing orientations of people with thyroid disease, which in turn is useful for avoiding generalisations about decision-making processes.

Politicised illness identities should be recognised as important realities of the discourse on thyroid disease. Additional research is needed to identify the extent of politicisation and its relation to factors such as illness types or geography. Acknowledging illness identities can further help with developing educational tools for patients. Many doctors may not be sufficiently aware of this phenomenon of politicisation and might therefore dismiss this reality. The individualisation demanded by today's patient-informed care practice (Gardiner, 2008; Snowdon et al., 2015) is also reflected in this study. Doctors should thus be supported in providing more personalised care to thyroid patients.

As activism increasingly uses social media for its demands (Neumayer \& Svensson, 2016) and health-seeking behaviour is shaped by social networks (Coiera, 2013), the paradigms and phenomena investigated in this study are of no small concern. While these may not be mainstream views, they can be seen as "pockets of highly-engaged patients and caregivers" (S. Fox, 2011) driving forward an important discourse. Ideally, embodied health movements lead to changes in the care system and have done so successfully in the past (Zavestoski et al., 2004). For thyroid disease, this would mean changes regarding the availability and cost of alternative medication, which will likely stay controversial. While illness experience has always been an important part of health activism (Brown et al., 2004), activism for thyroid disease needs to communicate its demands beyond this focus to become fully recognised as a reformative narrative (Zoller, 2005, 2012) offsetting existing inequalities. 


\section{Notes}

1. Complications could be especially severe in patients with cardiovascular diseases, in postmenopausal women, or in women antedating pregnancy (Madariaga et al., 2014).

2. Treatment options are related to different medical paradigmas, for instance more natural options like NDT (natural desiccated thyroid), are seen critically by many doctors adhering to the dominant protocol.

3. Related to this is a debate about what counts as unwanted content on social media, and companies like Facebook announced that they will no longer show health groups in recommendations (Raphael, 2018; Rodriguez, 2020).

4. Keywords were: hypothyroidism, hyperthyroidism, thyroid disease, Hashimoto's, Graves' disease, thyroid cancer.

5. On Facebook, the researcher participated in 39 pages and 29 groups as per $15^{\text {th }}$ September 2018. On Twitter, 260 followed accounts and 115 followers were counted as per $3^{\text {rd }}$ July 2019. This stage represents the view of an ordinary person.

6. Due to the auto(n)etnographic nature of this study, some activities are still ongoing, even though data collection has stopped, e.g. activities like blogging or communicating with people on social media.

7. Counting 1,620 members as per $29^{\text {th }}$ May 2020.

8. This was discussed in a personal interview with a thyroid advocate and followed-up in an email conversation on $12^{\text {th }}$ March 2019. However, the conference did not take place due lack of a formal patient organization and business plan.

9. Talking about personal illness narratives was an important component of interviewing, and was actively requested by participants.

10. This can be explained by the fact that interviewees often proactively requested this narrative from the researcher, but also because strategic themes of information curation and activism were frequently embedded in biographic narratives, helping to promote trust and to gain rapport.

11. Some participants were eager to know that the study is independent and not run by a medical company.

12. Another condition was cited as "cold temperature syndrome" and "high reverse T3". One person did not provide this data as part of the informed consent form. One person had both thyroid cancer and Hashimoto's, and 4 people either a partial or full thyroidectomy.

13. "How do you know that you are making the right decisions with regards to thyroid disease?"

14. This group is also called Thyroid Patients Canada.

15. These clusters can be mapped onto different strategic themes. 
16. This term is inspired by Sobo et al. and her "allegiance region" (Sobo et al., 2016, p. 534) based on the study of vaccination standpoint themes and decision landscapes.

17. This term is inspired by the Canadian Thyroid Patients campaign and the related interview. Thyroxine (T4) and triiodothyronine (T3) are both produced by the thyroid gland, as well as different forms of medication.

\section{Acknowledgements}

The application for Ethical Review of Research involving Human Subjects was endorsed by the Department of Media and Communication at City University of Hong Kong on $6^{\text {th }}$ April 2018 (expedited review). This work was supported by the Hong Kong PhD Fellowship Scheme (Research Grants Council of Hong Kong).

\section{References}

Balka, E., Krueger, G., Holmes, B. J., \& Stephen, J. E. (2010). Situating internet use: Information- seeking among young women with breast cancer. Journal of ComputerMediated Communication, 15(3), 389-411. https://doi.org/10.1111/j.1083-6101.2010.01506.x

Bennett, W. L. (2012). The personalization of politics: Political identity, social media, and changing patterns of participation. The ANNALS of the American Academy of Political and Social Science, 644(1), 20-39. https://doi.org/10.1177/0002716212451428

Bennett, W. L., \& Segerberg, A. (2012). The logic of connective action. Information, Communication \& Society, 15(5), 739-768. https://doi.org/10.1080/1369118X.2012.670661

Bennett, W. L., \& Segerberg, A. (2013). The logic of connective action: Digital media and the personalization of contentious politics. Cambridge University Press.

Bentley, J. P., \& Thaker, P. G. (2003). The influence of risk and monetary payment on the research participation decision making process. Journal of Medical Ethics, 30, 293-298. http://dx.doi.org/10.1136/jme.2002.001594

Bimber, B., Flanagin, A. J., \& Stohl, C. (2005). Reconceptualizin collective action in the contemporary media environment. Communication Theory, 15(4), 365-388. https://doi.org/10.1111/j.1468-2885.2005.tb00340.x

Böhm, A., Glaser, B., \& Strauss, A. (2004). Theoretical coding: Text analysis in grounded theory. In U. Flick, E. Kardoff, \& I. Steinke (Eds.), A companion to qualitative research (pp. 270-275). SAGE Publications. http://www.sxf.uevora.pt/wpcontent/uploads/2013/03/Böhm_2004.pdf

Brown, P., \& Zavestoski, S. (2004). Social movements in health: An introduction. Sociology of Health and Illness, 26(6), 679-694. https://doi.org/10.1111/j.0141-9889.2004.00413.x

Brown, P., Zavestoski, S., McCormick, S., Mayer, B., Morello-Frosch, R., \& Gasior Altman, R. (2004). Embodied health movements: New approaches to social movements in health. Sociology of Health and Illness, 26(1), 50-80. https://doi.org/10.1111/j.14679566.2004.00378.x 
Caliandro, A. (2018). Digital methods for ethnography: Analytical concepts for ethnographers exploring social media environments. Journal of Contemporary Ethnography, 47(5), 551578. https://doi.org/10.1177/0891241617702960

Charmaz, K. (1995). The body, identity, and self: Adapting to impairment. Sociological Quarterly, 36(4), 657-680. https://doi.org/10.1111/j.1533-8525.1995.tb00459.x

Coiera, E. (2013). Social networks, social media, and social diseases. British Medical Journal, 346(7912), Article: f3007. https://doi.org/10.1136/bmj.f3007

Cresswell, J. W. (2007). Qualitative inquiry and research design: Choosing among five approaches. SAGE Publications.

Das, R. (2019). Early motherhood in digital societies. Routledge. https://doi.org/10.4324/9781315167725

Diaz, J. A., Griffith, R. A., Ng, J. J., Reinert, S. E., Friedmann, P. D., \& Moulton, A. W. (2002). Patients' use of the internet for medical information. Journal of General Internal Medicine, 17(3), 180-185. https://doi.org/10.1046/j.1525-1497.2002.10603.x

Epstein, S. (1995). The construction of lay expertise: AIDS activism and the forging of credibility in the reform of clinical trials. Science, Technology \& Human Values, 20(4), 408 437. https://doi.org/10.1177/016224399502000402

Epstein, S. (1996). Impure science: AIDS, activism, and the politics of knowledge. University of California Press. https://www.ucpress.edu/book.php?isbn=9780520214453

Farkas, J., Schou, J., \& Neumayer, C. (2018). Platformed antagonism: Racist discourses on fake Muslim Facebook pages. Critical Discourse Studies, 15(5), 463-480. https://doi.org/10.1080/17405904.2018.1450276

Fox, N., \& Ward, K. (2006). Health identities: From expert patient to resisting consumer. Health, 10(4), 461-479. https://doi.org/10.1177/1363459306067314

Fox, S. (2011, May 12). The social life of health information, 2011 [Report]. https://www.pewresearch.org/internet/2011/05/12/the-social-life-of-health-information-2011

Fox, S., \& Duggan, M. (2013, January 15). Health online 2013 [Report]. http://www.pewinternet.org/2013/01/15/health-online-2013

Garber, J. R., Cobin, R. H., Gharib, H., Hennessey, J. V., Klein, I., Mechanick, J. I., PessahPollack, R., Singer, P. A. \& Woeber, K. A. (2012). Clinical practice guidelines for hypothyroidism in adults: Cosponsored by the American Association of Clinical Endocrinologists and the American Thyroid Association. Endocrine Practice, 18(6), 9881028. https://doi.org/10.4158/EP12280.GL

Gardiner, R. (2008). The transition from 'informed patient' care to 'patient informed' care. Studies in Health Technology and Informatics, 137, 241-256. http://www.ncbi.nlm.nih.gov/pubmed/18560085

Giraud, E. (2015). Subjectivity 2.0: Digital technologies, participatory media and communicative capitalism. Subjectivity, 8(2), 124-146. https://doi.org/10.1057/sub.2015.5

Glaser, B., Strauss, A., \& Strutzel, E. (1967). The discovery of grounded theory: Strategies for qualitative research. De Gruyter.

Guillemin, M., \& Gillam, L. (2004). Ethics, reflexivity, and "ethically important moments" in research. Qualitative Inquiry, 10(2), 261-280. https://doi.org/10.1177/1077800403262360

Hine, C. (2015). Ethnography for the internet: Embedded, embodied and everyday. Bloomsbury. 
ITT. (2017). ITT Campaign group: Improve thyroid treatment for millions of people. Stop the withdrawal of T3 [Petition]. Change.org. https://www.change.org/p/itt-campaign-groupimprove-thyroid-treatment-for-millions-of-people-stop-the-withdrawal-of-t3

Klandermans, B. (2004). The demand and supply of participation: Social psychological correlates of participation in social movements. In D. A. Snow, S. A. Soule, \& H. Kriesi (Eds.), The Blackwell companion to social movements (pp. 360-379). Blackwell Publishing.

Klandermans, P. G. (2014). Identity politics and politicized identities: Identity processes and the dynamics of protest. Political Psychology, 35(1), 1-22. https://www.jstor.org/stable/43785856

Klitzman, R., Albala, I., Siragusa, J., Nelson, K. N., \& Appelbaum, P. S. (2007). The reporting of monetary compensation in research articles. Journal of Empirical Research on Human Research Ethics, 2(4), 61-67. https://doi.org/10.1525/jer.2007.2.4.61

Kozinets, R. V. (2013). Netnography. Doing ethnographic research online. SAGE Publications.

Kozinets, R. V. (2015). Netnography: Redefined (2nd ed.). SAGE Publications.

Laverack, G. (2013). Health activism: Foundations and strategies SAGE Publications. https://doi.org/10.4135/9781446270004

Leahey, T. M., Doyle, C. Y., Xu, X., Bihuniak, J., \& Wing, R. R. (2015). Social networks and social norms are associated with obesity treatment outcomes. Obesity, 23(8), 1550-1554. https://doi.org/10.1002/oby.21074

Lupton, D. (2012). Medicine as culture: Illness, disease and the body. SAGE Publications. https://doi.org/10.4135/9781446254530

Madariaga, A. G., Santos Palacios, S., Guillén-Grima, F., \& Galofré, J. C. (2014). The incidence and prevalence of thyroid dysfunction in Europe: A meta-analysis. The Journal of Clinical Endocrinology \& Metabolism, 99(3), 923-931. https://doi.org/10.1210/jc.2013-2409

Mcmanus Holroyd, A. E. (2007). Interpretive hermeneutic phenomenology: Clarifying understanding. Indo-Pacific Journal of Phenomenology, 7(2), 1-12. https://doi.org/10.1080/20797222.2007.11433946

McMullan, M. (2006, October 1). Patients using the internet to obtain health information: How this affects the patient-health professional relationship. Patient Education and Counseling. Elsevier. https://doi.org/10.1016/j.pec.2005.10.006

Moini, J., Pereira, K., \& Samsam, M. (2020). Global impact of thyroid disorders. In Epidemiology of Thyroid Disorders (pp. 243-256). Elsevier. https://doi.org/10.1016/b978-012-818500-1.00011-6

Nelissen, S., Bulck, J. Van Den, \& Beullens, K. (2017). A typology of cancer information seeking, scanning and avoiding: Results from an exploratory cluster analysis. Information Research, 22(2), Article: 747. http://InformationR.net/ir/22-2/paper747.html

Neumayer, C., \& Rossi, L. (2018). Images of protest in social media: Struggle over visibility and visual narratives. New Media \& Society, 20(19), 4293-4310. https://doi.org/10.1177/1461444818770602

Neumayer, C., \& Svensson, J. (2016). Activism and radical politics in the digital age: Towards a typology. Convergence, 22(2), 131-146. https://doi.org/10.1177/1354856514553395

Orgad, S. (2006). The cultural dimensions of online communication: A study of breast cancer patients' Internet spaces. New Media \& Society, 8(6), 877-899. https://doi.org/10.1177/1461444806069643 
Ortner, S. B. (2005). Subjectivity and cultural critique. Anthropological Theory, 5(1), 31-52. https://doi.org/10.1177/1463499605050867

Perumal, S. S., Prasad, S., Surapaneni, K. M., \& Joshi, A. (2015). Health information-seeking behavior among hypothyroid patients at Saveetha Medical College and Hospital. Ethiopian Journal of Health Sciences, 25(2), 147-154. https://doi.org/10.4314/ejhs.v25i2.7

Phillips, W. (2018, May 22). The oxygen of amplification [Report]. Data \& Society. http://datasociety.net/output/oxygen-of-amplification/

Pitard, J. (2019). Autoethnography as a phenomenological tool: Connecting the personal to the cultural. In P. Liamputtong (Ed.), Handbook of research methods in health social sciences (pp. 1829-1845). Springer. https://doi.org/10.1007/978-981-10-5251-4_48

Postill, J. (2015). The logic of connective action: Digital media and the personalization of contentious politics [Book review]. The International Journal of Press/Politics, 20(4), 498500. https://doi.org/10.1177/1940161215599940

Primeau, L. A. (2003). Reflections on self in qualitative research: Stories of family. American Journal of Occupational Therapy, 57(1), 9-16. https://doi.org/10.5014/ajot.57.1.9

Raphael, R. (2018, August 24). Facebook deletes alternative health pages as the war on fake news escalates. Fast Company. https://www.fastcompany.com/90223904/facebook-deletesalternative-health-pages-as-the-war-on-fake-news-escalates

Rodriguez, S. (2020, September 17). Facebook cracking down on groups that give health advice. $C N B C$. https://www.cnbc.com/2020/09/17/facebook-to-limit-the-spread-of-groups-tied-toviolence-and-health-advice.html

Simon, B., \& Klandermans, B. (2001). Politicized collective identity: A social psychological analysis. American Psychologist, 54(4), 319-331. https://doi.org/https://doi.org/10.1037/0003-066X.56.4.319

Singer, J. (2008). The journalist in the network: A shifting rationale for the gatekeeping role and the objectivity norm. Tripodos, 1(23), 61-76. https://raco.cat/index.php/Tripodos/article/view/118912

Sloan, A., \& Bowe, B. (2014). Phenomenology and hermeneutic phenomenology: The philosophy, the methodologies, and using hermeneutic phenomenology to investigate lecturers' experiences of curriculum design. Quality and Quantity, 48(3), 1291-1303. https://doi.org/10.1007/s11135-013-9835-3

Snowdon, A. W., Alessi, C., Bassi, H., DeForge, R. T., \& Schnarr, K. (2015). Enhancing patient experience through personalization of health services. Healthcare Management Forum, 28(5), 182-185. https://doi.org/10.1177/0840470415588656

Sobo, E. J., Huhn, A., Sannwald, A., \& Thurman, L. (2016). Information curation among vaccine cautious parents: Web 2.0, Pinterest thinking, and pediatric vaccination choice. Medical Anthropology, 35(6), 529-546. https://doi.org/10.1080/01459740.2016.1145219

Tarricone, R. (2006). Cost-of-illness analysis: What room in health economics? Health Policy, 77(1), 51-63. https://doi.org/10.1016/j.healthpol.2005.07.016

Ulvenblad, P. (2020). knowledge communication and communication risks in healthcareProfessional amateur patients with thyroid disease show the way. In S. Durst \& T. Henschel (Eds.), Knowledge risk management (pp. 107-118). Springer. https://doi.org/10.1007/978-3030-35121-2_7 
Valente, T. W. (2010). Social networks and health: Models, methods, and applications. Oxford University Press.

Van Bulck, L., Luyckx, K., Goossens, E., Oris, L., \& Moons, P. (2019). Illness identity: Capturing the influence of illness on the person's sense of self. European Journal of Cardiovascular Nursing, 18(1), 4-6. https://doi.org/10.1177/1474515118811960

van Manen, M. (2007). Phenomenology of practice: Meaning-giving methods in phenomenological research and writing. Left Coast Press. http://www.maxvanmanen.com/files/2014/10/MvM-Phen-of-Practice-113.pdf

Van Stekelenburg, J., Van Leeuwen, A., \& Van Troost, D. (2013). Politicized identity. In D. A. Snow, D. della Porta, B. Klandermans, \& D. McAdam (Eds.), The Wiley-Blackwell encyclopedia of social and political movements (pp. 1-4). Blackwell Publishing. https://doi.org/10.1002/9781405198431.wbespm163

Vicari, S. (2017). Twitter and non-elites: Interpreting power dynamics in the life story of the (\#)BRCA twitter stream. Social Media and Society, 3(3). https://doi.org/10.1177/2056305117733224

Vicari, S., \& Cappai, F. (2016). Health activism and the logic of connective action. A case study of rare disease patient organisations. Information, Communication and Society, 19(11), 16531671. https://doi.org/10.1080/1369118X.2016.1154587

Viviani, M., \& Pasi, G. (2017). Credibility in social media: Opinions, news, and health information - a survey. Wiley Interdisciplinary Reviews: Data Mining and Knowledge Discovery, 7(5), Article: e1209. https://doi.org/10.1002/widm.1209

Wallace, R., Costello, L., \& Devine, A. (2018). Netnographic slog. International Journal of Qualitative Methods, 17(1), 1-13. https://doi.org/10.1177/1609406918797796

Wallendorf, M., \& Russel, W. B. (1989). Assessing trustworthiness in naturalistic consumer research. In E. C. Hirschmann (Ed.), Interpretive consumer research (pp. 69-84). Association for Consumer Research.

Waszak, P. M., Kasprzycka-Waszak, W., \& Kubanek, A. (2018). The spread of medical fake news in social media - The pilot quantitative study. Health Policy and Technology, 7(2), 115118. https://doi.org/10.1016/j.hlpt.2018.03.002

Winterich, J. A. (2011, November 10-13). "Sick and tired of feeling sick and tired": The politics of thyroid disease [Paper presentation]. National Women's Studies Association 32nd Annual Conference, Atlanta, GA, United States.

Zavestoski, S., Morello-Frosch, R., Brown, P., Mayer, B., McCormick, S., \& Altman, R. G. (2004). Embodied health movements and challenges to the dominant epidemiological paradigm. In D. J. Myers \& D. M. Cress (Eds.), Research in social movements, conflict and change. (Vol. 25, pp. 253-278). Emerald Group Publishing. https://doi.org/10.1016/S0163$786 \mathrm{X}(04) 25010-8$

Zoller, H. M. (2005). Health activism: Communication theory and action for social change health. Communication Theory, 15(4), 341-364. https://doi.org/10.1111/j.14682885.2005.tb00339.x

Zoller, H. M. (2012). communicating health: Political risk narratives in an environmental health campaign. Journal of Applied Communication Research, 40(1), 20-43. https://doi.org/10.1080/00909882.2011.634816 


\section{Author Biography}

Judith Schossböck is a PhD candidate at the Department for Media and Communication at City University Hong Kong and HKPFS award recipient. She is also an affiliated researcher at the Centre for E-Governance at Danube University, Austria, where she works as a research fellow. Furthermore, she is managing editor of the open access e-journal JeDEM (jedem.org) and scientific co-director of paraflows.at (symposium for digital arts and culture in Vienna). Her research interests cover digital activism, e-participation, online communities, social media, health communication, and technology ethics. 